\title{
BMJ Open Health-related quality of life in patients with non-communicable disease: study protocol of a cross-sectional survey
}

\author{
Lisa Van Wilder (D) , ${ }^{1}$ Els Clays, ${ }^{1}$ Brecht Devleesschauwer, ${ }^{2}$ Peter Pype (D) , ${ }^{1}$ \\ Pauline Boeckxstaens, ${ }^{1}$ Diego Schrans, ${ }^{1}$ Delphine De Smedt ${ }^{1}$
}

To cite: Van Wilder L, Clays E, Devleesschauwer B, et al. Health-related quality of life in patients with noncommunicable disease: study protocol of a crosssectional survey. BMJ Open 2020;10:e037131. doi:10.1136/ bmjopen-2020-037131

- Prepublication history for this paper is available online. To view these files, please visit the journal online (http://dx.doi. org/10.1136/bmjopen-2020037131).

Received 20 January 2020

Revised 26 June 2020

Accepted 30 July 2020
Check for updates

(C) Author(s) (or their employer(s)) 2020. Re-use permitted under CC BY-NC. No commercial re-use. See rights and permissions. Published by BMJ.

${ }^{1}$ Department of Public Health and Primary Care, Ghent University, Ghent, Belgium ${ }^{2}$ Epidemiology and Public Health, Sciensano, Brussels, Belgium

Correspondence to

Lisa Van Wilder;

lisa.vanwilder@ugent.be

\section{ABSTRACT}

Introduction Non-communicable diseases (NCDs) are associated with lower health-related quality of life (HRQoL). However, knowledge about those diseases and predictors with a greater impact on patients' HRQOL as well as knowledge on the complex relationship between $\mathrm{HRQOL}$ and comorbidities is lacking. The aim of this study is to assess the impact of NCDs on patients' HRQoL, with a focus on multimorbidity and socioeconomic status.

Methods and analysis A primary care-based crosssectional study is conducted in Flanders (Belgium). Study participants ( $\geq 18$ years) are medically diagnosed with at least one of the following diseases: cardiometabolic disorders, mental disorders and musculoskeletal disorders. A minimum of 50 general practitioners will participate to recruit participants (convenient sample) and a total of 531 patients will be enrolled (voluntary response sample). Each participant will complete a paper-based questionnaire to gather research outcomes. Statistical analyses will be performed using multiple linear regression models with $\mathrm{HRQ}$ oL as main outcome parameter, adjusted for possible confounders. This study will generate new evidence on the key predictors of HRQoL in patients with NCDs, and particularly provide new insights in multimorbidity to improve the quality of care in primary care, to support patients' self-management and to allocate resources more effectively.

Ethics and dissemination The study has been approved by the Ethical Committee of Ghent University Hospital, Ghent, Belgium (reference number: B670201939629) prior to the beginning of the recruitment. Study results will be disseminated through peer-reviewed publications and conference presentations.

\section{INTRODUCTION}

Non-communicable diseases (NCDs) remain the leading cause of morbidity and mortality worldwide, responsible for 36 million deaths annually, with a rapidly rising prevalence due to population growth and ageing. ${ }^{12}$ Furthermore, chronically ill patients often suffer from multimorbidity, which can be defined as the co-occurrence of several chronic conditions within one person. Depending on the age class, multimorbidity occurs in 13\%-72\% of the general population worldwide. ${ }^{3}$ In

\section{Strengths and limitations of this study}

This study will improve the understanding of the key predictors of self-perceived health status in patients with non-communicable disease and multimorbidity in a primary care setting.

- Data are collected through a paper-based questionnaire consisting of diverse validated instruments.

- This study uses objective medical diagnoses obtained via general practitioners, limiting the risk of self-reported bias.

- Participants are recruited through voluntary response sample which potentially introduces selection bias.

2018, $15 \%$ of the Belgian population aged 15 years and older suffered from multimorbidity and this percentage increased strongly with age, going up to $42 \%$ for people aged 75 years and older. ${ }^{4}$

NCDs are associated with a substantial burden of disease for the patients, their caregivers and the society as a whole. ${ }^{56}$ During the past decades, the interest into chronically ill patients' health-related quality of life (HRQoL) as a key health outcome indicator is growing due to the absence of an adequate cure for several NCDs, resulting in a shift from problem-oriented care to goal-oriented care. $^{2}$ Many studies revealed a significant decrease in HRQoL in patients with NCD and indicated HRQoL as an important predictor of morbidity and mortality. ${ }^{78}$

While numerous studies have addressed the impact of single NCDs on HRQoL, a thorough understanding of the influence of several predictors and risk indicators (eg, socioeconomic status) is lacking. Additionally, little is known about the impact of multimorbidity on HRQoL outcomes as most studies focus on one particular disease. Although an inverse relationship is seen between the number of NCDs and HRQoL, a simple count of the number of NCDs does not completely 
capture the association between both. ${ }^{9}$ When the outcome of interest is HRQoL, looking at clusters of specific NCDs has been explored by previous research, however, this association needs to be further investigated..$^{1011}$

To date, research on NCDs and multimorbidity usually focuses on the elderly population, resulting in insufficient knowledge on HRQoL in younger populations. ${ }^{12}$ Some studies however indicated an increased level of mental problems among younger populations groups, but the impact is not fully known. ${ }^{13}$ Moreover, the impact on HRQoL is often measured by one specific instrument, albeit disease-specific or not, while meaningful information could be obtained by capturing HRQoL from multiple instruments. ${ }^{14}$

In agreement with the United Nations Sustainable Development Goals to reduce premature mortality from NCDs by one-third through prevention and better treatment by 2030, the Belgian Federal Government has prioritised the integrated care for chronically ill patients in order to increase patients' quality of life, to improve the quality of care and to use the allocated resources more effectively. ${ }^{1516}$ Knowledge about those diseases and predictors with a greater impact on patients' HRQoL as well as knowledge on the complex relationship between HRQoL and comorbidities can guide healthcare providers in their clinical practice and policy makers in their priority setting regarding screening, prevention and disease treatment.

The aim of this study is to provide insight in HRQoL outcomes and their predictors in patients with NCD, with a focus on multimorbidity and socioeconomic status in the context of a primary care setting. The outcomes of this study will estimate the relative effects of socioeconomic status and multimorbidity on HRQoL across different categories of NCDs. The following main study objectives can be defined:

Objective 1: this study wants to assess the impact of NCDs on patients' HRQoL by identifying the key predictors associated with an impaired HRQoL and by allowing for comparison across different disease groups and socioeconomic classes. In this study, there will be a special focus on socioeconomic status, due to its substantial impact on the healthy lifespan. In Belgium, the difference in the total number of healthy life years between highest and lowest educated persons amounts to 10.4 years in men and 13.5 years in women. ${ }^{17}$

Objective 2: this study wants to determine the impact of multimorbidity on HRQoL in patients with NCDs attending primary care.

\section{METHODS}

\section{Study population and design}

A primary care-based cross-sectional study was designed to investigate the association between NCDs and patients' HRQoL in Flanders (Belgium). The study participants are adult patients ( $\geq 18$ years) who are medically diagnosed ( $\geq 6$ months) with at least one of the following diseases, in various degrees of severity: (1) cardiometabolic disorders;
(2) mental disorders; or (3) musculoskeletal disorders. Any NCD that fits within the three disease groups can be included. The selection of these three disease groups was based on evidence confirming the lower HRQoL in all the above-mentioned disease groups compared with other diseases. ${ }^{18}$ Study participants with insufficient understanding of Dutch to complete the questionnaire or to give informed consent as well as study participants with a major cognitive impairment are excluded.

\section{Sample size calculation}

To achieve the research aims, multiple linear regression models will be conducted assessing several key predictors associated with HRQoL as primary outcome. The regression models should allow for controlling the effect of main confounders (eg, sex, age, educational attainment), and for including interaction terms with psychosocial variables. A sample size calculation showed that the minimum required sample for a multiple regression study including 10 predictors with a medium anticipated effect size was 118 , given a desired statistical power level of $80 \%$ and a probability level of $5 \% .{ }^{19-22}$ The sample size was increased with $50 \%$ to allow for testing interaction effects. This study has three clusters of disease groups (cardiometabolic disorders, mental disorders and musculoskeletal disorders), therefore stratified analyses require a triple sample size. Hence, an a priori sample size of minimum 531 participants is targeted. This sample size will also widely cover analysing clinically relevant differences between a number of chronic disease subgroups. Based on the conclusions of a systematic review by Norman $e t$ $a l$, the clinically relevant difference will be set at half a SD which appears to be the threshold of discrimination for changes in HRQoL for NCDs. ${ }^{23}$ Using a statistical power level of $80 \%$ and a probability level of $5 \%$, information on 76 patients per disease cluster is needed (1) to assess the HRQoL (based on SF-36) in each patients' group with a $5 \%$ precision and (2) to allow for comparisons across groups. $^{24-34}$

\section{Recruitment of participants}

Patient recruitment is organised through general practitioners (GPs) with independent practices and GP practices within community health centres across all the provinces in Flanders. First, a number of GP practices located across urban and rural regions willing to participate in this study are identified through convenience sampling based on their contact with a so-called 'local quality group' (LOK group). A LOK group consists of fellow GPs who share and critically discuss their medical practices in order to improve the quality of care. The Flemish GP association (Domus Medica) disseminated a call asking whether LOK groups are interested in a presentation related to the subject of the study for a LOK group meeting. At these meetings, the researchers briefly present the study and they ask GPs willingness to cooperate in the study. GPs are asked to identify patients within their practice after validation of the eligibility criteria. GPs will explain briefly 
the purposes of the study to the patients and invite them to participate through voluntary response sample. Interested GPs receive more detailed information to ensure the aim of the study and the data collection process are understood. To achieve the targeted sample size of 531 participants, a minimum of 50 general practices, each distributing at least 20 questionnaires, is aimed for.

\section{Data collection}

A paper-based questionnaire is developed based on the literature and consists of diverse validated instruments. Expert reviews from GPs, academic researchers and epidemiologists were used to evaluate the questionnaire. The questionnaire was pilot tested by patients, from different age classes, diagnosed with a NCD in order to evaluate the feasibility of the questionnaire in terms of readability, comprehensibility and duration. The questionnaire, including informed consent, is distributed to the participant by the GP at consultation. Each questionnaire has a unique ID code. The questionnaire takes approximately $30 \mathrm{~min}$ to gather patient information and research outcomes and is filled in by the patient at home. Completed questionnaires can be returned by post via a prepaid return envelope, which is enclosed with all questionnaires. The questionnaire can also be given back to the GP at later consultation. The pathway for recruiting participants and data collection is illustrated in figure 1 .

Reminder phone calls to the GPs take place every 2 months. In order to motivate the GPs to distribute the

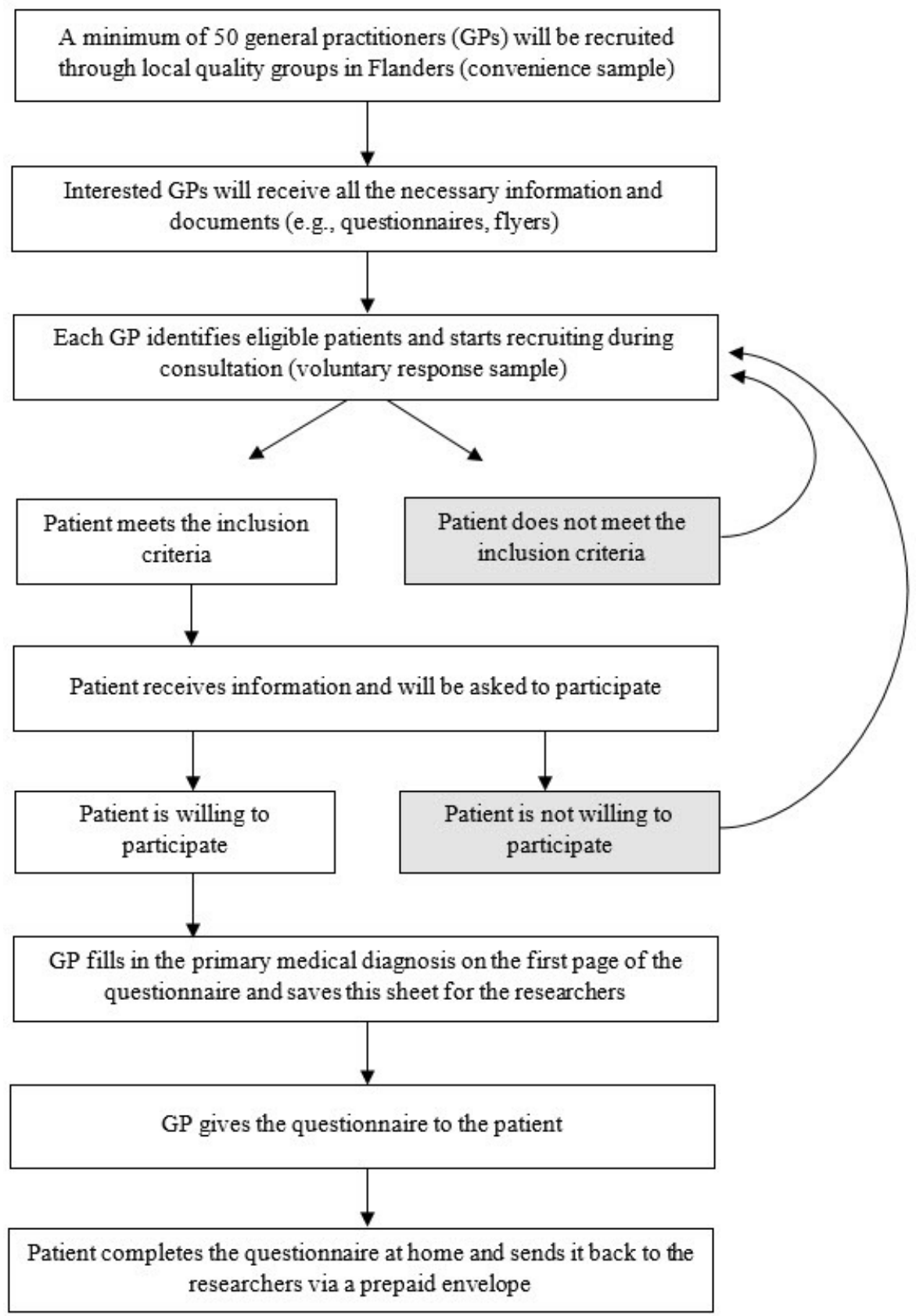

Figure 1 Pathway for recruiting participants and data collection. 


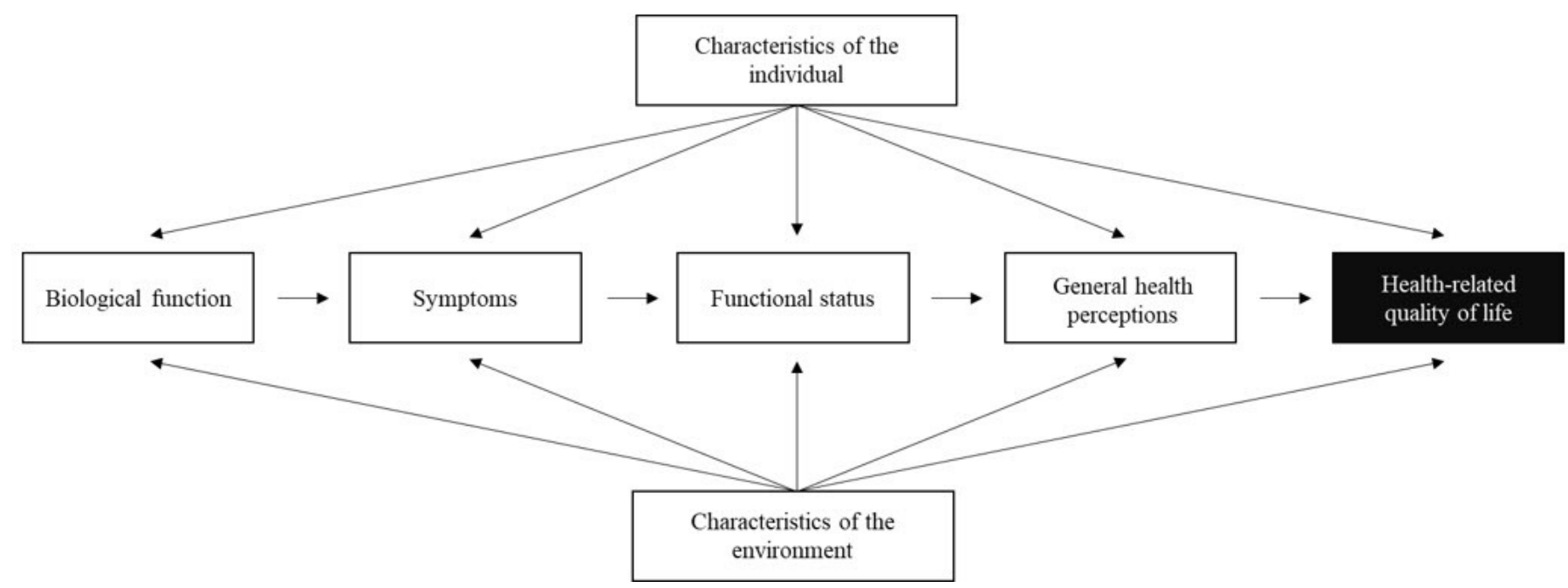

Figure 2 The revised Wilson and Cleary model for health-related quality of life is used as theoretical framework.

questionnaires, the number of questionnaires already received from their practice is communicated. In addition, an individualised tri-monthly newsletter is sent to all GPs with an update of the current status of the study.

\section{Research outcomes and instruments}

The revised model of Wilson and Cleary is used as theoretical framework to measure HRQoL and its predictors in patients with NCDs (figure 2). ${ }^{35}$ First, information on the characteristics of the chronically ill patients and their environment are collected. Second, information on the five health concepts in patient outcomes are collected: biological function, symptoms, functional status, general health perceptions and overall HRQoL. ${ }^{36} 37$

\section{Characteristics of chronically ill patients and their environment}

Based on the ecological model of McLeroy et al, five levels of influencing factors are linked with the health concepts determining HRQoL, namely: intrapersonal factors, interpersonal factors, institutional factors, community factors and public policy. The intrapersonal factors contain characteristics of the individual (eg, sociodemographic characteristics, personality traits, modifiable risk factors). The remaining four factors are identified as environmental characteristics. $^{38}$

\section{Sociodemographic characteristics}

The following sociodemographic characteristics are gathered: age, sex, region of residence (ie, Flanders, Brussels or Wallonia), nationality, marital status, size of the household, educational attainment (ie, primary school, lower secondary education, higher secondary education, higher education, doctoral degree), occupational status, income level and National Registration Number. The latter can track study participants in the National Register database providing information on possible death of the participants, which can be useful for future research.

\section{Socioeconomic status}

Socioeconomic status represents a core concept in this study because evidence indicates that socioeconomic deprivation is associated with worse HRQoL outcomes. ${ }^{39} 40$ Socioeconomic status is a combined measure of an individual's social and economic position relative to others and commonly based on three main indicators: educational level, income level and occupational status. ${ }^{414}$ Educational level will be measured as the highest level of education attained by the patient based on the International Standard Classification of Education. ${ }^{43}$ Income level will be measured by asking patients' monthly per capita household income (total net household income/ number of members). Occupational status will be based on the following categories: employed, unemployed and not in the work field (eg, pension, disability). These three indicators of socioeconomic status will be studied separately as the different measures give additional information.

\section{Personality traits}

Since research has confirmed that personality traits are related to various health outcomes, the interest in this field is growing. ${ }^{44}$ Different personality traits are measured using the short Big Five Inventory (BFI-10) to allow a quick assessment of a person's degree of extraversion, agreeableness, conscientiousness, emotional stability and intellect/openness. ${ }^{45}$ The BFI-10 is very brief and suitable for applications in large-scale surveys as it takes $1 \mathrm{~min}$ to complete. The instrument consists of 10 items where each item is scored on a 5-point Likert scale ranging from 'strongly disagree' to 'strongly agree'. The Dutch version has been demonstrated to be reliable and valid. $^{45}$

\section{Sense of coherence}

During the last decades, several studies assessed the impact of sense of coherence on quality of life. These studies showed that stronger levels of sense of coherence 
predict positive health outcomes and better overall quality of life. ${ }^{46-48}$ Evaluating sense of coherence is therefore of interest, especially in NCDs, in order to understand why people under stress stay healthy, while others not. ${ }^{4649}$ Sense of coherence is measured using the brief Antonovsky's Sense of Coherence Scale (SOC), which contains 13 items covering three dimensions: comprehensibility (the extent to which events are perceived as making sense, that they are ordered, consistent and structured), manageability (the extent to which a person feels he/she can cope) and meaningfulness (how much one feels that life makes sense and challenges are worthy of commitment). ${ }^{49}$ Responses are reported by a semantic scale ranging from 1 (never or very seldom) to 7 (very often). SOC scores range from 13 to 91 , and a higher score indicates higher SOC. The structural validity of the Dutch SOC-13 has been confirmed. ${ }^{50}$

\section{Self-efficacy}

Self-efficacy is the belief in one's competence to attempt difficult or novel tasks and to cope with adversity arising from specific demanding situations. ${ }^{51}$ Higher levels of self-efficacy are related to an increase in the number of satisfying social relations, which may be beneficial to HRQoL outcomes. ${ }^{51}{ }^{52}$ Since there is a lack of research investigating general self-efficacy and HRQoL among patients with NCD, this study assesses the relationship between both. General self-efficacy is measured using the Dutch version of the General Self-Efficacy Scale (GSES). ${ }^{53} 54$ The GSES is a 10-item psychometric scale that is designed to assess optimistic self-beliefs to cope with a variety of difficult demands in life. The total score is calculated by the sum of all items. Scores range between 10 and 40, with higher scores indicating more self-efficacy. The psychometric quality of the instrument is sufficient. ${ }^{53}$

\section{Health literacy}

Low health literacy levels are observed in the general population, and specifically in patients with NCDs. ${ }^{55-57}$ In recent decades, evaluating individuals' health literacy has received increased attention, as it is associated with numerous negative health outcomes, such as lower quality of life, but the relationship is still unclear. Therefore, a better understanding of the relationship between health literacy and HRQoL is necessary. ${ }^{55}$ The HLS-EU-Q6 is used as a short scale of the European Health Literacy Survey (HLS-EU-Q) ${ }^{58}$ This tool consists of six items addressing self-reported difficulties in accessing, understanding, appraising and applying information in tasks concerning decision-making in healthcare, disease prevention and health promotion. ${ }^{59}$ Responses are reported from 1 (very difficult) to 4 (very easy). The scale score varies between 1 and 4 , with higher scores indicating better health literacy. Correlations of the HLS-EU-Q6 with the index of the long scale HLS-EU-Q were high. ${ }^{60}$

\section{Patient enablement}

Research demonstrated that improvements in patient enablement may result in better quality of life.$^{61}$ Therefore, this study includes patient enablement as a predictor of HRQoL. The Patient Enablement Instrument (PEI) focuses on the impact of a clinical consultation for an acute or chronic disease in primary care on a patient's self-perceived ability to understand and cope with health issues and the disease itself. The PEI consists of six questions that reflect patient enablement. ${ }^{62}$ The responses are scored on a 3-point scale ('same or less/not applicable' $=0$, 'better $/$ more' $=1$ and 'much better $/$ much more' $=2)$. The total PEI score ranges between 0 and 12 to indicate low (0-4), medium (score 5-9) and high enablement (10-12). A Dutch version was conducted by the researchers via forward-backward translation.

\section{Modifiable risk factors for chronic diseases}

This study collects information on risk factor prevalence by assessing the following items: current smoking status, alcohol consumption (quantities per week), leisure time physical activity (almost entirely sedentary, light physical activity, more vigorous physical activity, highly vigorous physical activity) and anthropometry (self-reported weight and height). The latter will be used to calculate body mass index (BMI). Participants with a BMI between 25 and $29.9 \mathrm{~kg} / \mathrm{m}^{2}$ will be considered overweight and participants with a BMI $\geq 30$ will be considered obese.

\section{Work ability}

Three questions of the Work Ability Index (WAI) questionnaire are used. The WAI is used to assess work ability with questions about workers' health status, their capabilities and mental and physical demands of their work. ${ }^{6364}$

\section{Health care use}

Patients who use primary care services more frequently have been reported to have lower HRQoL outcomes. Therefore, healthcare resource use is measured by the following items: number of hospitalisations/emergency room visits/specialist consultations in the last 6 months and number of GP consultations/other outpatient visits/ home help services (eg, nurse visits, home help visits, cleaning services) in the last month.

\section{Pharmacological treatment}

It is important to assess the influence of polypharmacy on HRQoL, especially in NCDs, given the increased risk of adverse health outcomes. ${ }^{65}$ Medication use is assessed with the question "Which medication are you currently taking?" Although there exists no universal definition, polypharmacy will be defined as the use of five or more medications concomitantly. ${ }^{66}$

\section{Social environmental characteristics}

The influence of social environmental characteristics (eg, interpersonal factors, social influences) on health outcomes is obtained by questioning social support and informal caregiving. Social support is measured using the 
six-item shortened version of the Social Support Questionnaire (F-SozU) by Fydrich et al. ${ }^{67} 68$ This valid and reliable instrument is well accepted in epidemiological contexts to assess social support in the general population. A Dutch version was conducted by the researchers via forward-backward translation. Responses are rated on a 5-point Likert scale, ranging from 1 (does not apply) to 5 (exactly applicable). The total range is from 0 to 30 , with higher values representing higher perceived and received social support. Informal care is measured by the following items: number of informal caregivers, relationship with the informal caregiver (eg, spouse, parent), how many days per week they receive informal care and tasks of the informal caregiver (eg, dressing, bathing).

\section{Biological function}

Biological functions encompass functioning of molecular, cellular and organ systems that can be analysed by laboratory tests, physical assessment and medical diagnosis. ${ }^{35}$ In this study, biological functions are restricted to the medical diagnosis documented via the participating GP.

\section{Multimorbidity}

Multimorbidity is measured by a self-developed list based on a multimorbidity questionnaire (MM-21), and documents 24 self-reported NCDs in primary care ${ }^{69}$ Participants have to indicate for each condition 'yes' or 'no', 'yes' may only be filled in for the conditions that have been confirmed by a doctor or for which the participant is taking prescribed drugs. ${ }^{69}$ Participants are also asked in which year the disease was diagnosed. To date, consensus on defining, assessing and measuring multimorbidity is still lacking as each method has its specific strengths and limitations. However, defining multimorbidity as the presence of two or more chronic diseases at the same time in one individual is not universally accepted, especially when highly prevalent conditions (eg, hypertension, osteoporosis) are included as these result in higher prevalence rates. ${ }^{70}$ This study will therefore use a cut-off value of $\geq 3$ chronic disease to define multimorbidity. However, sensitivity analyses will be conducted with other cut-off values.

\section{Symptoms}

Biological functions are directly linked with symptoms, which is the second patient outcome. Symptoms can be stated as a patient's perception of an abnormal physical, emotional or cognitive state. ${ }^{35}$ This study uses a symptomspecific validated measure to assess non-physical symptoms: the Hospital Anxiety and Depression Scale (HADS) ${ }^{71}$ The HADS is a 14 -item brief instrument to determine presence of anxiety and depressive states. The HADS compromises two scales, each consisting of seven items. ${ }^{71} 72$ A maximum score of 21 can be achieved per scale. The higher the overall score, the higher the levels of anxiety and depression.

\section{Functional status}

Functional status can be defined as 'the ability of an individual to perform specific tasks in multiple domains such as physical function, social function, role function and psychological function', and can be measured by both objective and subjective (ie, self-perceived health status) instruments. ${ }^{37}$

\section{Self-perceived health status}

This study uses the 12-item Short Form Health Survey (SF-12) as a generic self-perceived health status instrument to assess patients' functional health and well-being by measuring both physical and mental functioning components. In this study, the 12-item version instead of the 36 -item version is preferred as it can be easily completed in 5 min. The instrument contains 12 items including eight domains (physical functioning, role-physical, bodily pain, general health, vitality, social functioning, roleemotional and mental health). The summary scores, on a scale from 0 to 100 , will be calculated to represent physical functioning and mental functioning. Higher scores indicate better self-perceived health status. The SF-12 has been confirmed as a valid and reliable instrument for measuring health perception in a general population for primary care. ${ }^{73}$ Moreover, a second generic instrument is used to measure one's self-perceived health status, the EQ-5D-5L, which is composed of two parts: a descriptive system and a visual analogue scale (VAS). The descriptive system consists of five health-related domains (mobility, self-care, usual activities, pain/discomfort, anxiety/ depression) defined by five severity levels (no problems, slight problems, moderate problems, severe problems, extreme problems) from which an EQ-5D index score, or utility score, can be calculated. A utility is defined on a scale anchored at 0 (death) and 1 (perfect health), and can represent negative values for health states perceived worse than death. ${ }^{74}$ The VAS provides a self-rating of the general health status on a scale from 0 (worst imaginable health) to 100 (best imaginable health). In this study, selfperceived health status is used as a proxy for HRQoL.

\section{General health perceptions}

General health perceptions are subjective ratings which combine all the previous health concepts and can be measured with a single global question, asking people to rate their health ranging from poor to excellent. This study uses the SF-12 which has this single item incorporated by the following question: "In general, would you say your health is excellent/very good/fair/poor?"

\section{IIIness perception}

Research confirms that positive illness perceptions are related to better quality of life. ${ }^{75} 76$ This study aims to determine whether illness perceptions differ across NCDs and clusters thereof. The Dutch version of the brief Illness Perception Questionnaire (IPQ-B) is used for assessing patients' cognitive and emotional representations of their illness including consequences, timeline, personal control, treatment control, identity, coherence, concern, emotional response and causes. ${ }^{77} 78$ The questionnaire uses a scale from 0 to 10 to assess cognitive 
illness representations (item 1-5), emotional representations (item 6 and 8 ) and illness comprehensibility (item 7). A low score on items number 1, 2, 5, 6 and 8 indicates that the illness is perceived as benign while a low score on the items 3, 4 and 7 indicates that the illness is perceived as threatening. By reversing these three items it is possible to compute an overall score. A higher score reflects a more threatening view of the illness. The reliability and validity of the IPQ-B are supported in different chronic illness populations. ${ }^{77}$ The face and content properties of the Dutch version were found to be acceptable. ${ }^{79}$

The conceptual HRQoL model of Wilson and Cleary represents the relationships between the multiple outcomes. It is hypothesised that the following outcomes would have an adverse effect on patients' HRQoL: patients who have multiple conditions, patients who perceive high levels of anxiety/depression and patients who perceive lower functional ability. Moreover, we expect that the following outcomes would result in lower HRQoL experienced by patients with NCD: lower socioeconomic status, high risk factor prevalence (smoking, high alcohol consumption, high BMI), maladaptive coping, frequent healthcare use, polypharmacy, limited social support, negative illness perceptions and lower levels of selfefficacy, sense of coherence, patient enablement and health literacy.

\section{Statistical methods}

Descriptive statistics will be performed in order to describe the sample of study participants. For normally distributed continuous variables, means and SD will be calculated, for non-normally distributed continuous variables, medians and IQRs will be calculated. If normally distributed, independent sample T-tests for continuous variables and $\chi^{2}$ tests for categorical variables will be used to compare characteristics of the study participants. Non-parametric tests will be used when variables are not normally distributed.

Multiple linear and logistic regression models will be built assessing the key predictors associated with HRQoL as main outcome parameter, adjusted for possible confounding variables (sex, age, educational attainment, health-related risk behaviour, symptom status). Different substudies will be conducted and for each substudy different models will be built, assessing crude and adjusted relations between predictor variables and HRQoL. The primary analysis will include an indicator variable for NCD category, socioeconomic status, marital status, presence of comorbidity, anxiety/depression, social support, sense of coherence and self-efficacy as independent variables. Interactions between NCD categories and other key variables (eg, socioeconomic status) will be tested. In case of interaction ( $p$-value $<0.10$ for the interaction term), stratification per NCD group will be conducted.

Given the exploratory nature of the study, advanced mediation analysis testing for specific causal pathways will not be performed. Multicollinearity will be assessed when building multiple regression models, excluding variables in case they correlate extensively (eg, Pearson's $r \geq 0.60$ ) with others. The statistical analyses will be performed using IBM SPSS statistics and a p-value of 0.05 will be considered as statistically significant. Each model will be corrected for multiple testing, using the Bonferroni method, since there are two outcome variables for HRQoL.

\section{PATIENT AND PUBLIC INVOLVEMENT}

Neither patients nor the public were involved in the design of the study. Patients were invited to pilot test the paper-based questionnaire in order to evaluate the feasibility of the questionnaire in terms of readability, comprehensibility and duration.

\section{DISCUSSION}

The main strength of this study is its contribution to the necessity for evidence on key predictors associated with an impaired HRQoL in patients with NCD. The results can support patient management of (multiple) NCDs within the primary care setting, which is of major interest to healthcare providers and policy makers in national and international context.

A methodological strength of this study is the use of objective medical diagnoses, which limits the risk of selfreported bias. In this way, our study distinguishes from other studies often including self-reported medical diagnosis, for example, the Belgian Health Interview Survey. ${ }^{80}$ Another strength is the use of international, validated instruments to assess HRQoL and its predictors. Regarding the former, this study includes two different instruments (EQ-5D-5L and SF-12) to evaluate HRQoL, and could therefore compare the results of both instruments. Furthermore, the sample size includes participants from all age categories ( $\geq 18$ years) while many studies focus on older populations, since chronic diseases are more prevalent in the elderly. ${ }^{81} 82$ Another strength is that the questionnaire has been pilot tested by patients of interest to improve the feasibility of the questionnaire. A final strength is that this study is developed to minimise time investment for GPs in order to maximise GP recruitment rates.

Several limitations need to be taken into account. First, this study has a cross-sectional study design and could therefore not detect causal relationships. Second, recruitment of patients follows a voluntary response procedure, which is vulnerable to sampling bias due to a high non-response rate and results in a less representative sample population. ${ }^{83}$ Women, older individuals and individuals with higher educational attainment will likely be over-represented in our sample as they are more prone to return postal questionnaires. ${ }^{84} 85$ Moreover, the prevalence of health-related risk behaviour (eg, smoking, alcohol consumption, physical inactivity) as well as impaired health status may be underestimated due to selective non-response effects and social desirability bias. ${ }^{86}{ }^{87}$ In response to the possible selection bias, an additional qualitative study based on in-depth face-to-face interviews will be initiated in difficult-to-reach patients 
(eg, lower socioeconomic status, more severe illness) to allow further investigation of the impact of NCDs on these patients' HRQoL. ${ }^{86}$

This cross-sectional study will improve the understanding of the key predictors of self-perceived health status in patients with NCDs, and particularly provide new insights in multimorbidity. The knowledge gained is necessary to improve the quality of care in primary care, to support patients' self-management and to allocate resources more effectively.

\section{ETHICS AND DISSEMINATION}

The study has been designed according to the principles of the Declaration of Helsinki. The study has been approved by the Ethical Committee of Ghent University Hospital, Ghent, Belgium on 17 April 2019 (reference number: B670201939629) prior to the beginning of the recruitment. Participation is voluntary and all participants will provide informed consent. Study results will be disseminated through peer-reviewed publications and international conference presentations. Deliverables will be presented to policy makers, GPs and the broader audience.

Contributors The acquired funding was done by DDS. DDS, EC, PP and LVW have made substantial contribution to the concept and design of the study. PB and DS gave input on the development of the data collection process. BD provided important intellectual content. This protocol paper was written by DDS and LVW. All authors read and approved the final manuscript.

Funding This work was supported by BOF (Bijzonder Onderzoeksfonds; Special Research Fund); grant number 01N02618.

Competing interests None declared.

Patient and public involvement Patients and/or the public were not involved in the design, or conduct, or reporting, or dissemination plans of this research.

Patient consent for publication Not required.

Provenance and peer review Not commissioned; externally peer reviewed.

Open access This is an open access article distributed in accordance with the Creative Commons Attribution Non Commercial (CC BY-NC 4.0) license, which permits others to distribute, remix, adapt, build upon this work non-commercially, and license their derivative works on different terms, provided the original work is properly cited, appropriate credit is given, any changes made indicated, and the use is non-commercial. See: http://creativecommons.org/licenses/by-nc/4.0/.

\section{ORCID iDs}

Lisa Van Wilder http://orcid.org/0000-0003-4394-2623

Peter Pype http://orcid.org/0000-0003-2273-0250

\section{REFERENCES}

1 World Health Organization (WHO). Noncommunicable diseases, 2018. Available: http://www.who.int/topics/noncommunicable diseases/en/ [Accessed 15 Jan 2019].

2 Megari K. Quality of life in chronic disease patients. Health Psychol Res 2013;1:27.

3 Fortin M, Stewart M, Poitras ME, et al. A systematic review of prevalence studies on multimorbidity: toward a more uniform methodology. Ann Fam Med 2012;10:142-51.

4 Sciensano. Health interview survey, Sciensano, 1997-2018. Available: https://his.wiv-isp.be/SitePages/Home.aspx2019 [Accessed 16 Nov 2019].

5 GBD 2015 DALYs and HALE Collaborators. Global, regional, and national disability-adjusted life-years (DALYs) for 315 diseases and injuries and healthy life expectancy (HALE), 1990-2015: a systematic analysis for the global burden of disease study 2015. Lancet 2016;388:1603-58.
6 Van Wilder L, Rammant E, Clays E, et al. A comprehensive catalogue of EQ-5D scores in chronic disease: results of a systematic review. Qual Life Res 2019;28:1-9.

$7 \mathrm{Xu} \mathrm{RH}$, Cheung AWL, Wong EL-Y. Examining the health-related quality of life using EQ-5D-5L in patients with four kinds of chronic diseases from specialist outpatient clinics in Hong Kong SAR, China. Patient Prefer Adherence 2017;11:1565-72.

8 De Smedt D, Clays E, Annemans L, et al. Self-reported health status in coronary heart disease patients: a comparison with the general population. Eur J Cardiovasc Nurs 2015;14:117-25.

9 Fortin M, Lapointe L, Hudon C, et al. Multimorbidity and quality of life in primary care: a systematic review. Health Qual Life Outcomes 2004;2:51.

10 Fortin M, Dubois M-F, Hudon C, et al. Multimorbidity and quality of life: a closer look. Health Qual Life Outcomes 2007;5:52.

11 Wang L, Palmer AJ, Cocker F, et al. Multimorbidity and health-related quality of life (HRQoL) in a nationally representative population sample: implications of count versus cluster method for defining multimorbidity on HRQoL. Health Qual Life Outcomes 2017;15:7.

12 Makovski TT, Schmitz S, Zeegers MP, et al. Multimorbidity and quality of life: systematic literature review and meta-analysis. Ageing Res Rev 2019;53:100903.

13 Pati S, Swain S, Knottnerus JA, et al. Health related quality of life in multimorbidity: a primary-care based study from Odisha, India. Health Qual Life Outcomes 2019;17:116.

14 Wang H-M, Beyer M, Gensichen J, et al. Health-related quality of life among general practice patients with differing chronic diseases in Germany: cross sectional survey. BMC Public Health 2008;8:246.

15 Paulus D, Van den Heede K, Gerkens S, et al. Development of a national position paper for chronic care: example of Belgium. Health Policy 2013;111:105-9.

16 Assembly G. Sustainable development goals. Available: http://www. igbp.net/download/18.62dc35801456272b46d51/1399290813740/ NL82-SDGs.pdf [Accessed 26 Nov 2019].

17 Renard F, Devleesschauwer B, Van Oyen H, et al. Evolution of educational inequalities in life and health expectancies at 25 years in Belgium between 2001 and 2011: a census-based study. Arch Public Health 2019;77:6.

18 GBD 2017 Disease and Injury Incidence and Prevalence Collaborators. Global, regional, and national incidence, prevalence, and years lived with disability for 354 diseases and injuries for 195 countries and territories, 1990-2017: a systematic analysis for the global burden of disease study 2017. Lancet 2018;392:1789-858.

19 Cohen P, West SG, Aiken LS. Applied multiple regression/correlation analysis for the behavioral sciences. Psychology Press, 2014.

20 Cohen J. Statistical Power Analysis Jbr the Behavioral. In: Sciences Hillsdale (NJ): Lawrence Erlbaum associates, 1988: 18-74.

21 Soper DS. A-priori sample size calculator for multiple regression, 2020. Available: http://www.danielsoper.com/statcalc [Accessed 19 Mar 2020].

22 Abramowitz M, Stegun IA. Handbook of mathematical functions. Dover, New York, 1965.

23 Norman GR, Sloan JA, Wyrwich KW. Interpretation of changes in health-related quality of life: the remarkable universality of half a standard deviation. Med Care 2003;41:582-92.

24 Kweon S, Sohn MK, Jeong JO, et al. Quality of life and awareness of cardiac rehabilitation program in people with cardiovascular diseases. Ann Rehabil Med 2017;41:248-56.

25 Seidel UK, Gronewold J, Volsek M, et al. Physical, cognitive and emotional factors contributing to quality of life, functional health and participation in community dwelling in chronic kidney disease. PLoS One 2014:9:e91176.

26 Schure MB, Borson S, Nguyen $\mathrm{HQ}$, et al. Associations of cognition with physical functioning and health-related quality of life among COPD patients. Respir Med 2016;114:46-52.

27 Jansson S-A, Axelsson M, Hedman L, et al. Subjects with wellcontrolled asthma have similar health-related quality of life as subjects without asthma. Respir Med 2016;120:64-9.

28 Lomper K, Chudiak A, Uchmanowicz I, et al. Effects of depression and anxiety on asthma-related quality of life. Pneumonol Alergol Pol 2016;84:212-21.

29 Vladetić M, Jančuljak D, Butković Soldo S, et al. Health-related quality of life and ways of coping with stress in patients with migraine. Neurol Sci 2017;38:295-301.

30 Müller-Nordhorn J, Nolte CH, Rossnagel K, et al. The use of the 12 -item short-form health status instrument in a longitudinal study of patients with stroke and transient ischaemic attack. Neuroepidemiology 2005;24:196-202.

31 Zioga E, Kazakos K, Dimopoulos E, et al. Adherence and quality of life in patients with type II diabetes mellitus in northern Greece. Mater Sociomed 2016;28:258-62. 
32 Rodrigues-De-Souza DP, Fernández-De-Las-Peñas C, Martín-Vallejo $\mathrm{FJ}$, et al. Differences in pain perception, health-related quality of life, disability, mood, and sleep between Brazilian and Spanish people with chronic non-specific low back pain. Braz J Phys Ther 2016;20:412-21.

33 Verkerk K, Luijsterburg PAJ, Heymans MW, et al. Prognosis and course of pain in patients with chronic non-specific low back pain: a 1-year follow-up cohort study. Eur J Pain 2015;19:1101-10.

34 Nolet PS, Côté P, Kristman VL, et al. Is neck pain associated with worse health-related quality of life 6 months later? a populationbased cohort study. Spine J 2015;15:675-84.

35 Wilson IB, Cleary PD. Linking clinical variables with health-related quality of life. A conceptual model of patient outcomes. JAMA 1995;273:59-65.

36 Ojelabi AO, Graham Y, Haighton C, et al. A systematic review of the application of Wilson and Cleary health-related quality of life model in chronic diseases. Health Qual Life Outcomes 2017;15:241.

37 Ferrans CE, Zerwic JJ, Wilbur JE, et al. Conceptual model of healthrelated quality of life. J Nurs Scholarsh 2005;37:336-42.

38 McLeroy KR, Bibeau D, Steckler A, et al. An ecological perspective on health promotion programs. Health Educ Q 1988;15:351-77.

39 Sommer I, Griebler U, Mahlknecht P, et al. Socioeconomic inequalities in non-communicable diseases and their risk factors: an overview of systematic reviews. BMC Public Health 2015;15:914.

40 Mielck A, Vogelmann M, Leidl R. Health-related quality of life and socioeconomic status: inequalities among adults with a chronic disease. Health Qual Life Outcomes 2014;12:58.

41 Adler NE, Boyce T, Chesney MA, et al. Socioeconomic status and health. The challenge of the gradient. Am Psychol 1994;49:15.

42 Cox AM, McKevitt C, Rudd AG, et al. Socioeconomic status and stroke. Lancet Neurol 2006;5:181-8.

43 Statistics Ulf. International standard classification of education: ISCED 2011: UNESCO Institute for Statistics Montreal 2012.

44 Hudek-Knezević J, Kardum I. Five-factor personality dimensions and 3 health-related personality constructs as predictors of health. Croat Med J 2009;50:394-402.

45 Rammstedt B, John OP. Measuring personality in one minute or less: a 10-item short version of the big five inventory in English and German. Journal of research in Personality 2007;41:203-12.

46 Eriksson M, Lindström B. Antonovsky's sense of coherence scale and its relation with quality of life: a systematic review. J Epidemiol Community Health 2007;61:938-44.

47 Surtees P, Wainwright N, Luben R, et al. Sense of coherence and mortality in men and women in the EPIC-Norfolk United Kingdom prospective cohort study. Am J Epidemiol 2003;158:1202-9.

48 Poppius E, Tenkanen L, Hakama M, et al. The sense of coherence, occupation and all-cause mortality in the Helsinki heart study. Eur $J$ Epidemiol 2003;18:389-93.

49 Antonovsky A. The structure and properties of the sense of coherence scale. Soc Sci Med 1993;36:725-33.

50 Luyckx K, Goossens E, Apers S, et al. The 13-item sense of coherence scale in Dutch-speaking adolescents and young adults: structural validity, age trends, and chronic disease. Psychologica Belgica 2012;52:351-68.

51 Bandura A. Self-Efficacy mechanism in human agency. Am Psychol 1982;37:122-47.

52 Cramm JM, Strating MMH, Roebroeck ME, et al. The importance of general self-efficacy for the quality of life of adolescents with chronic conditions. Soc Indic Res 2013;113:551-61.

53 Jerusalem M, Schwarzer R. The general self-efficacy scale 1979.

54 Teeuw B, Schwarzer R, Jerusalem M. Dutch general self-efficacy scale 2010;1994:22

55 Couture Éva Marjorie, Chouinard M-C, Fortin M, et al. The relationship between health literacy and quality of life among frequent users of health care services: a cross-sectional study. Health Qual Life Outcomes 2017;15:137.

56 Kutner M, Greenburg E, Jin Y, et al. The health literacy of America's adults: results from the 2003 national assessment of adult literacy. NCES 2006-483. National Center for Education Statistics 2006.

57 Kirsch IS. Adult literacy in America: a first look at the results of the National adult literacy survey: ERIC 1993

58 Sorensen K, Pelikan JM, Rothlin F, et al. Health literacy in Europe: comparative results of the European health literacy survey (HLS-EU) Eur J Public Health 2015;25:1053-8.

59 Sørensen K, Pelikan JM, Röthlin F, et al. Health literacy in Europe: comparative results of the European health literacy survey (HLS-EU) Eur J Public Health 2015;25:1053-8.

60 Pelikan JM, Röthlin F, Ganahl K. Measuring comprehensive health literacy in general populations: validation of instrument, indices and scales of the HLS-EU study. 6th annual health literacy research conference Bethesda, Maryland: Hyatt Regency, 2014. Available: http://www bumc bu edu/healthliteracyconference/files/2014/06/ Pelikan-et-al-HARC-2014-fin pdf

61 Correia de Sousa J, Pina A, Cruz AM, et al. Asthma control, quality of life, and the role of patient enablement: a cross-sectional observational study. Prim Care Respir J 2013;22:181.

62 Howie JG, Heaney DJ, Maxwell M, et al. A comparison of a patient enablement instrument (PEI) against two established satisfaction scales as an outcome measure of primary care consultations. Fam Pract 1998;15:165-71.

63 van den Berg TIJ, Elders LAM, de Zwart BCH, et al. The effects of work-related and individual factors on the work ability index: a systematic review. Occup Environ Med 2009;66:211-20.

64 Tuomi KIJ, Jahkola A, et al. Work ability index. Helsinki: Finnish Institute of Occupational Health, 1998.

65 Meraya AM, Dwibedi N, Sambamoorthi U. Polypharmacy and health-related quality of life among US adults with arthritis, medical expenditure panel survey, 2010-2012. Prev Chronic Dis 2016;13:E132.

66 World Health Organization (WHO). Medication safety in polypharmacy, 2019. Available: https://apps.who.int/iris/bitstream/ handle/10665/325454/WHO-UHC-SDS-2019.11-eng.pdf?ua=1 [Accessed 26 Nov 2019].

67 Fydrich T, Sommer G, Tydecks S, et al. Fragebogen Zur sozialen unterstützung (F-SozU): Normierung Der Kurzform (K-14). Zeitschrift für Medizinische Psychologie 2009;18:43-8.

68 Kliem S, Mößle T, Rehbein F, et al. A brief form of the perceived social support questionnaire (F-SozU) was developed, validated, and standardized. J Clin Epidemiol 2015;68:551-62.

69 Fortin M, Almirall J, Nicholson K. Development of a research tool to document self-reported chronic conditions in primary care. J Comorb 2017;7:117-23.

70 Fortin M, Stewart M, Poitras M-E, et al. A systematic review of prevalence studies on multimorbidity: toward a more uniform methodology. Ann Fam Med 2012;10:142-51.

71 Zigmond AS, Snaith RP. The hospital anxiety and depression scale. Acta Psychiatr Scand 1983;67:361-70.

72 Spinhoven P, Ormel J, Sloekers PP, et al. A validation study of the hospital anxiety and depression scale (HADS) in different groups of Dutch subjects. Psychol Med 1997;27:363-70.

73 Brazier JE, Harper R, Jones NM, et al. Validating the SF-36 health survey questionnaire: new outcome measure for primary care. BMJ 1992;305:160-4.

74 Devlin NJ, Krabbe PFM. The development of new research methods for the valuation of EQ-5D-5L. Eur J Health Econ 2013;14:S1-3.

75 Foxwell R, Morley C, Frizelle D. Illness perceptions, mood and quality of life: a systematic review of coronary heart disease patients. $J$ Psychosom Res 2013;75:211-22.

76 Tiemensma J, Gaab E, Voorhaar M, et al. Illness perceptions and coping determine quality of life in COPD patients. Int $J$ Chron Obstruct Pulmon Dis 2016;11:11.

77 Broadbent E, Petrie KJ, Main J, et al. The brief illness perception questionnaire. J Psychosom Res 2006;60:631-7.

78 De Raaij E, Schroder C, Kaptein A. Ziekteperceptie vragenlijst IPQ-K 2007

79 de Raaij EJ, Schröder C, Maissan FJ, et al. Cross-cultural adaptation and measurement properties of the brief illness perception questionnaire-Dutch language version. Man Ther 2012;17:330-5.

80 Demarest S, Van der Heyden J, Charafeddine R, et al. Methodological basics and evolution of the Belgian health interview survey 1997-2008. Arch Public Health 2013;71:24.

81 Zhao C, Wong L, Zhu Q, et al. Prevalence and correlates of chronic diseases in an elderly population: a community-based survey in Haikou. PLoS One 2018;13:e0199006.

82 Wolff JL, Starfield B, Anderson G. Prevalence, expenditures, and complications of multiple chronic conditions in the elderly. Arch Intern Med 2002;162:2269-76.

83 Rosenthal R. The volunteer subject. Human relations 1965;18:389-406.

84 Criqui $\mathrm{MH}$. Response bias and risk ratios in epidemiologic studies. Am J Epidemiol 1979;109:394-9.

85 Criqui MH, Barrett-Connor E, Austin M. Differences between respondents and non-respondents in a population-based cardiovascular disease study. Am J Epidemiol 1978;108:367-72.

86 Cheung KL, Ten Klooster PM, Smit C, et al. The impact of non-response bias due to sampling in public health studies: a comparison of voluntary versus mandatory recruitment in a Dutch national survey on adolescent health. BMC Public Health 2017;17:276.

87 Jacobsen BK, Thelle DS. The Tromsø heart study: responders and non-responders to a health questionnaire, do they differ? Scand $J$ Soc Med 1988;16:101-4. 